This is the accepted manuscript of the article, which has been published in Kaunisto M.,Höglund M. \& Rickman P. (Eds.) Changing Structures: Studies in constructions and complementation. Studies in Language Companion Series (195). John Benjamins Publishing Company. 2018. 978-90-272-0054-9. http:// doi.org/10.1075/slcs.195.07saa

\title{
Sentential complementation of propose in recent British English ${ }^{1}$
}

\author{
Veera Saarimäki \\ University of Tampere
}

This article examines the sentential complementation of propose from 1780 to the 1990s. The study is based on previous research on the use of the verb in the Corpus of Late Modern English Texts and the British National Corpus. The focus of the article is on control theory, and it tracks changes in the complement patterns and control structure of propose. The examination of the corpora shows that throughout the data, the to-infinitive is the most frequent complement of propose, followed by the that-clause and -ing clause. The to-infinitive has increased its proportion at the expense of other patterns. The control structure of propose is complex, as it allows subject, object, PP object as well as unspecified control, the latter increasing in use. The data indicate that most changes occur between 1780 and 1920, reinforcing the idea that the Late Modern English period was a time of significant change in the complementation systems of many predicates.

Keywords: English, corpus linguistics, complementation, control, propose

\footnotetext{
${ }^{1}$ I would like to thank Juhani Rudanko for mentoring me in the writing of the MA thesis this article is based on. I am forever grateful for all the support and encouragement he has given me throughout the years. I would also like to thank the two anonymous reviewers for their valuable feedback on the article.
} 


\section{Introduction}

In the field of modern English linguistics it is generally acknowledged that, as heads of phrasal constructions, verbs have an effect on some of the items that follow them. Consider the following examples drawn from the Corpus of Late Modern English Texts (CLMET):

(1) Bellarius also proposed to carry her out into the forest, and there celebrate her funeral with songs and solemn dirges, as was then the custom. (1807 Lamb, Tales from Shakespeare)

(2) He proposed that if the man returned he should not be interfered with, but merely watched from the other side of the glass door. (1902 Bennett, The Grand Babylon Hotel)

(3) The young woman whom I mentioned to you proposed rowing me across the water amongst the rocks. (1796 Wollstonecraft, Letters on Sweden, Norway and Denmark)

Sentences 1-3 exemplify the most frequently used sentential complements of the verb propose, i.e. the to-infinitive, that-clause and -ing clause, in use. This article tracks the development of these three as well as other, less common, sentential complement patterns of propose from 1780 to the end 
of the twentieth century with the help of two corpora, the CLMET and the British National Corpus (BNC). Diachronic surveys in the complementation of this particular verb have not been previously conducted with this set of corpus data, so the aim is to contribute to the scholarly treatment of verb complementation with this focused study.

The article is based on my MA thesis (Saarimäki 2014), which studied both the sentential and non-sentential complementation of propose extensively, drawing on theories such as theta theory (e.g. Haegeman 1991: 41ff), the extraction principle (e.g. Vosberg 2003: 308), and control theory (e.g. Davies and Dubinsky 2004). In the current work the theoretical framework has been limited to control theory, as the control structure of propose provided some of the most interesting findings in the MA thesis.

The paper starts by looking at propose in the literature to form an initial idea of the sentential complements that can be expected to occur with the verb in the corpus data, as well as the control tendencies of the verb (Section 2). Section 3 introduces the data and methods, and Section 4 discusses the findings. Conclusions are presented in Section 5.

\section{Propose in the literature}

This section looks at the sentential complementation of propose on the basis of well-known dictionaries and grammars, introduces control theory, and 
summarises any remarks on the control structure of propose found in the dictionaries and grammars. The findings act as a starting point for the analysis of the authentic corpus data.

\subsection{Propose in dictionaries}

In order to see what kinds of complementation patterns the verb propose has been presented as selecting, two dictionaries that differ in both style and purpose were consulted: the Oxford English Dictionary (OED), which focuses on listing, describing and exemplifying the senses of words, and Poutsma's (MS) unpublished Dictionary of Constructions, which focuses on the different constructions in which words occur. Both dictionaries provide multiple senses for the verb, two of which are most likely to occur with sentential complementation and thus the most relevant for the current paper. These two senses, as defined in the OED (s.v. propose), are given in Table 1.

Table 1. The relevant senses of propose (OED, s.v. propose).

1. With infinitive or verbal noun as object. To set before oneself as something to be done; to intend, purpose, or design.

2. With clause, infinitive, or simple object. To put forward or suggest as a scheme, plan, or course of action; to recommend or advocate that 
something be done.

Moving on to the syntax of propose, Table 2 summarises the sentential complement patterns identified in the examples provided by the dictionaries.

Table 2. Sentential complement patterns of propose in the dictionaries.

\begin{tabular}{|l|l|}
\hline OED & Poutsma \\
\hline to-infinitive & to-infinitive \\
to + NP + to-infinitive & $\mathrm{NP}+$ to-infinitive \\
that-clause & to $+\mathrm{NP}+$ to-infinitive \\
-ing clause & that-clause \\
& -ing clause \\
& poss. + -ing clause \\
\hline
\end{tabular}

As the table shows, propose occurred with a total of six patterns in the dictionaries, five of which were exemplified in both. Of the five, the NP + to-infinitive pattern stands out; Poutsma (MS, s.v. propose), in fact, notes that it is "an unusual one". Indeed, the pattern is only exemplified once in each dictionary:

(4) Dei..may propose hem to gete or noye pe townes. (OED: $1441 \mathrm{H}$. Nicolas) 
(5) The monopoly plan .. is proposed to be applied to sago and sugar. (Poutsma: Daily Mail)

The four other complement patterns seem to be more common and can be expected to be found in both the CLMET and the BNC, whereas the poss. + -ing clause pattern might be rarer, as indicated by its absence from the $O E D$ :

(6) You proposed our confessing our faults. (Poutsma: Hardy, Tess)

\subsection{Propose in grammars}

For further information on the syntax of propose, three influential grammars were considered. A summary of the sentential complement patterns given for propose in the grammars is presented in Table 3.

Table 3. Sentential complement patterns of propose in the three grammars.

\begin{tabular}{|c|c|c|}
\hline Quirk et al. (1985) $A$ & Biber et al (1999) & Huddleston and \\
\hline Comprehensive & Longman Grammar & Pullum (2002) \\
\hline Grammar of the & of Spoken and & Cambridge Grammar \\
\hline English Language & Written English & of the English \\
\hline & & Language \\
\hline to-infinitive & that-clause & to-infinitive \\
\hline
\end{tabular}




\begin{tabular}{|l|l|l|}
\hline $\mathrm{NP}+$ to-infinitive & to $+\mathrm{NP}+$ that-clause & for $+\mathrm{NP}+$ to-infinitive \\
that-clause & -ing clause & that-clause \\
to $+\mathrm{NP}+$ that-clause & $\mathrm{NP}+$-ing clause & to $+\mathrm{NP}+$ that-clause \\
-ing clause & & -ing clause \\
\hline
\end{tabular}

The representation of propose in the grammars is relatively similar to the dictionaries in that the most frequently exemplified patterns, to-infinitive, that-clause and -ing clause, can be found in both Tables 2 and 3. However, there is more variation between the grammars than there is between the OED and Poutsma. Quirk et al. (1985: 1181-1183) list the NP + to-infinitive pattern that Poutsma (MS, s.v. propose) considered "unusual”, whereas Huddleston and Pullum (2002: 1226) indicate that propose can also take a for + NP + to-infinitive complement. Biber et al. (1999) do not mention the to-infinitive in their list of complements of propose, whereas all three grammars state that the that-clause complement can be preceded by to $+\mathrm{NP}$, a pattern which did not occur in either the OED or Poutsma.

\subsection{Control theory and propose}

According to Huddleston and Pullum (2002: 1194), a distinction can be made between two types of verbs:

(7) Liz hoped to convince them. 
(8) Liz seemed to convince them.

In (7), Liz is an argument of hope, whereas Liz is not an argument of seem in (8). In other words, Liz is doing the hoping in (7), but it is not possible for her to be "seeming" in (8). This distinction is caused by the fact that hope is a control predicate and seem is an NP movement predicate. As propose functions similarly to hope, the concept of control requires further discussion.

In control theory, it is argued that the predicate in the complement clause has a subject, although it is often not structurally present. The argument is supported by theta theory: according to the theta criterion, “[e]ach argument is assigned one and only one theta role [and] [e]ach theta role is assigned to one and only one argument” (Haegeman 1991: 46). The first half of the criterion is relevant here, as Huddleston and Pullum (2002: 1194) point out that in (7) Liz seems to be assigned two theta roles: Experiencer by hope and Agent by convince. Since the theta criterion forbids this, convince must have an understood subject, PRO, that is coreferential with, i.e. controlled by, the subject of the matrix clause, Liz:

(7') Liz hoped [PRO to convince them.]

In ( $\left.7^{\prime}\right)$ the problem has been solved, as the theta role Agent can be assigned to the understood subject PRO. 
The controlling element is not always the subject of the matrix clause, as exemplified in (9), adapted from Huddleston and Pullum (2002: 1193):

(9) Pat persuaded Kim [PRO to travel by bus].

In (9), PRO is controlled by, and is thus coreferential with, the object of persuade: Kim.

To start defining the control structure of propose, the literature discussed above was reviewed. According to Quirk et al. (1985: 1187), propose is always a subject control verb, when it is followed by a simple toinfinitive $^{2}$ or an -ing clause. They make no remarks on control in relation to any other complement patterns of propose, nor do the other grammars.

Poutsma (MS, s.v. propose), on the other hand, comments on the infinitival complement patterns of propose as follows: “...the subject of the action indicated by the infinitive may be the speaker(s), the person(s) spoken to, or the speaker and the person(s) spoken to together.” The first of these refers to subject control, whereas in the second type the NP in the to + $\mathrm{NP}+$ to-infinitive or $\mathrm{NP}+$ to-infinitive patterns controls the subject of the to-infinitive. ${ }^{3}$ This means that propose is both a subject and an object control verb, although it has to be noted that in object control the controlling

\footnotetext{
${ }^{2}$ As opposed to the to $+\mathrm{NP}+$ to-infinitive and NP + to-infinitive patterns.

${ }^{3}$ I interpret Poutsma's (MS, s.v. propose) second type of control to refer to (PP) object control constructions in which the controlling element is explicitly present, and decided to include all instances without an explicit controller in the third type, although the understood subject might in some cases be "the person(s) spoken to" rather than "the speaker and the person(s) spoken to together”.
} 
element is traditionally an NP directly following the matrix verb, rather than an NP in a PP. To differentiate between control in the to $+\mathrm{NP}+$ to-infinitive and NP + to-infinitive patterns, I will call the former PP object control. The final type, henceforth unspecified control, refers to a kind of combination of subject and object control, in which the controller of the understood subject is not explicitly present, as in Poutsma's (MS, s.v. propose) example:

(10) He proposed to go into the first public-house we should find open. (Poutsma: Smol., Rod. Rand)

On the basis of Poutsma's analysis, the subject of go in (10) is both he and the addressee(s), which suggests that the sentence could be rephrased as $\left(10^{\prime}\right)$ :

(10') He proposed that we should go into the first public-house we should find open.

However, it could be argued that he could be making the proposition to the hearers (we) alone without any intention of going to the public-house himself. In this case the to + NP element could be considered to have been dropped, and (10) could be rephrased as (10"): 
(10") He proposed to us to go into the first public-house we should find open.

On the basis of example (10), it seems to be possible to omit the controlling item, the PP preceding the to-infinitive, from the sentence. This is an interesting quality of propose, as Rudanko (1989: 138), discussing similar constructions and their underlying structures, notes that with verbs that occur in the PP object control pattern "the PP is in general much less freely omissible” than with subject control constructions. The statement is closely related to Bach's generalisation (based on the works of Bach 1979; 1980), which has been formulated by Rizzi (1986: 503) as follows: "In object control structures the object NP must be structurally represented.” If the generalisation is thought to include prepositional objects, propose violates it.

To summarise, the control structure of propose is diverse. It will be interesting to see whether examples of all four types of control can be found in the authentic data, and whether changes have occurred in their use over time.

\section{Data and methods}


The historical data for the study were collected from the Corpus of Late Modern English Texts (CLMET). The second (1780-1850; 3.7 million words) and third (1850-1920; 4 million words) periods of the CLMET were searched for all forms of propose, i.e. propose, proposes, proposed and proposing, the corpus being untagged at the time. The smaller, original version of the CLMET was chosen over the more recently updated extended version and version 3.0 of the corpus, as it was large enough to provide an appropriate number of tokens for the study.

The more recent data, containing material from the 1960s to 1990s, was drawn from the British National Corpus (BNC) with a lemma search. The search was limited to the imaginative prose domain (16.5 million words) of the BNC to keep the number of hits reasonable and to ensure that the data would be stylistically similar to the CLMET data. It should be noted, however, that the CLMET is more varied in its text types than the imaginative prose domain of the BNC, which could have an effect on the findings.

After the data was collected, the tokens were examined manually to identify the complement of propose in each instance. In cases where distinguishing between a complement and an adjunct was problematic, I relied on Somers's (1984: 516-517) do so test, according to which the “do so phrase can be the proform of anything up to the entire predication [...], [but] the minimum element that can be substituted is the predicate plus any complements” (1984: 517). Thus, (12) below is rendered ungrammatical by 
the complement of propose, "a toast”, not being included in the proform do so.

(11) Jake proposed a toast at the birthday party and Mary did so at the graduation.

(12) *Jake proposed a toast at the birthday party and Mary did so a toast at the graduation.

In addition to identifying the complements, irrelevant tokens were discarded. There were a total of 12 irrelevant tokens in the second period of the CLMET (CLMET2), 14 in the third (CLMET3) and one in the BNC. All of these were examples of the adjectival use of proposed. After the manual pruning, the number of tokens to be analysed is 298 for the CLMET2, 377 for the CLMET3, and 368 for the BNC. Because of the differences in the total word counts of the subcorpora, raw counts are normalised to frequencies per 1,000,000 words in the discussion below.

\section{$4 \quad$ Findings and discussion}

This section discusses developments in the sentential complementation and control structure of propose from 1780 to the end of the twentieth century. 


\subsection{Sentential complementation of propose}

\subsubsection{Overview}

The total number of tokens in the subcorpora is 1,043 , divided rather equally between the three periods: 298 in the CLMET2, 377 in the CLMET3 and 368 in the BNC. However, if these numbers are compared to the total word counts of the subcorpora, 3.7, 4 and 16.5 million words respectively, it is quite apparent that the overall use of propose has decreased notably in the twentieth century. Figure 1 illustrates the change.

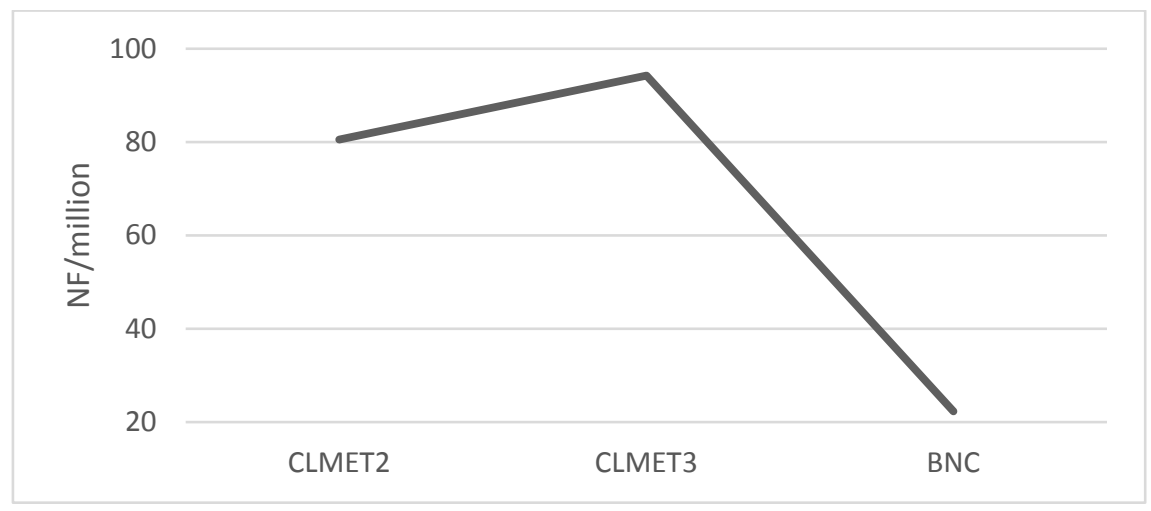

Figure 1. Changes in the frequency of propose from 1780 to the 1990 s.

In the period $1780-1850$, the frequency of the verb propose is 80.5 per million words, after which it rises to 94.3 in the period 1850-1920. During the approximately 40-year gap in the data, the number drops to roughly one fourth, i.e. 22.3 occurrences per million words. One reason for the sharp decline might be that the CLMET contains treatises and other non-fictional 
text types that favour more formal verbs, whereas the imaginative prose domain of the BNC consists entirely of fictional texts. However, the difference in style is unlikely to be the only reason for the drop, as the earlier data does contain plenty of tokens from fictional material.

Between the three subcorpora, propose occurs with nine different sentential complement patterns, although no one subcorpus contained all nine complement types alone. Three patterns are variations of the toinfinitive, and there are two variations of both that-clauses and -ing clauses in the data. The two remaining complement patterns are the quote and the wh-clause, both of which were only found in two of the subcorpora. The patterns will be discussed in four sections: to-infinitive patterns, -ing clause patterns, that-clause patterns, and other patterns.

Because of the decrease in the overall use of propose, it is likely that most complement patterns will have gone through a similar change. For this reason, relying on normalised frequencies (NFs) alone would not provide a comprehensive picture of the developments that have taken place in the complement structure of propose. In addition to the NFs, the proportion of each complement of the total number of tokens will be taken into account.

\subsubsection{To-infinitive patterns}

Throughout the data, the to-infinitive is the most common sentential complement of propose, and after the CLMET2 period, it is the most common complement of propose overall: 
(13) When Aunt Sarah arrived, proposing to take them both to live with her in Coniston, he had utterly refused to go. (BNC: F99 36)

The pattern has a total of 75 tokens in the CLMET2, 163 in the CLMET3 and 128 in the BNC. Figure 2 shows the NF of the to-infinitive as well as its proportion in each subcorpus.

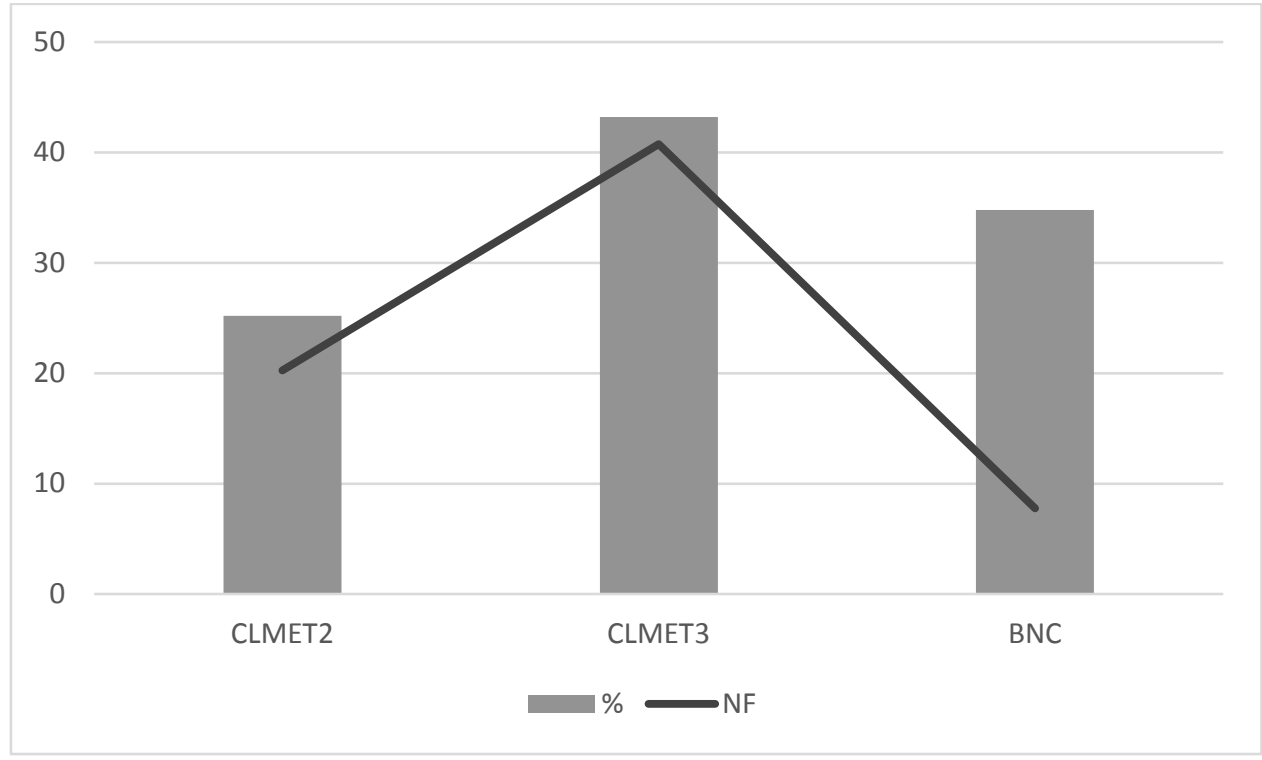

Figure 2. Normalised frequency and proportion of the to-infinitive complement in the subcorpora.

As Figure 2 shows, both the NF and the proportion of the to-infinitive as much as double from the CLMET2 to the CLMET3, after which the NF drops to less than one fourth in the BNC, following the overall frequency of 
the verb. The proportion of the complement pattern does not decrease as steeply, but instead settles to the middle ground between the two earlier periods. Closer inspection reveals that the steep increase of the complement in the CLMET3 can be pinpointed to one text: out of the 163 to-infinitives, as many as 57 occur in one text, namely Booth’s In Darkest England and the Way out:

(14) I propose to multiply their number, to develop their usefulness, and to make them the threshold of the whole Scheme. (CLMET3: 1890 Booth, In Darkest England and the Way out)

If this text is removed from the calculations, the to-infinitive has a NF of 27.2 and a proportion of $35.3 \%$ of all complements of propose in the CLMET3. Both numbers point to an increase in the use of the pattern in the period 1850-1920, after which the situation has stabilised, the to-infinitive accounting for $34.8 \%$ of the tokens in the BNC.

The two other to-infinitive patterns found in the data are to $+\mathrm{NP}+$ toinfinitive and NP + to-infinitive. The former occurs seven times in both the CLMET2 and the CLMET3, which indicates a slight decrease in both NF and proportion before the pattern, according to the BNC data, falls out of use: 
(15) It is just what I proposed to her to do--to have crossed the Alps with me, to sail on sunny seas... (CLMET2: 1823 Hazlitt, Liber Amoris)

Considering that none of the grammars listed the pattern as a possible complement of propose, the development is not surprising.

The NP + to-infinitive complement is rare in all subcorpora, with just two tokens in the CLMET2, five in the CLMET3 and one in the BNC. Judging by the few available instances of the pattern, it tends to occur in a passivized sentence and has a formal feel about it:

(16) Apart from the independent agencies employed to prosecute this class on enquiries, which it is proposed to very largely increase, the Army possesses in itself peculiar advantages for this kind of investigation (CLMET3: 1890 Booth, In Darkest England and the Way out)

On the basis of the corpus data, the inclusion of the pattern in Quirk et al. (1985: 1181-1183) as a complement of propose feels trivial considering that other rare patterns are not mentioned.

\subsection{3 -ing clause patterns}

The -ing clause occurs as a complement of propose a total of 23 times in the CLMET2, 12 in the CLMET3 and 11 in the BNC. Figure 3 shows how the 
normalised frequency and proportion of the pattern have decreased over time.

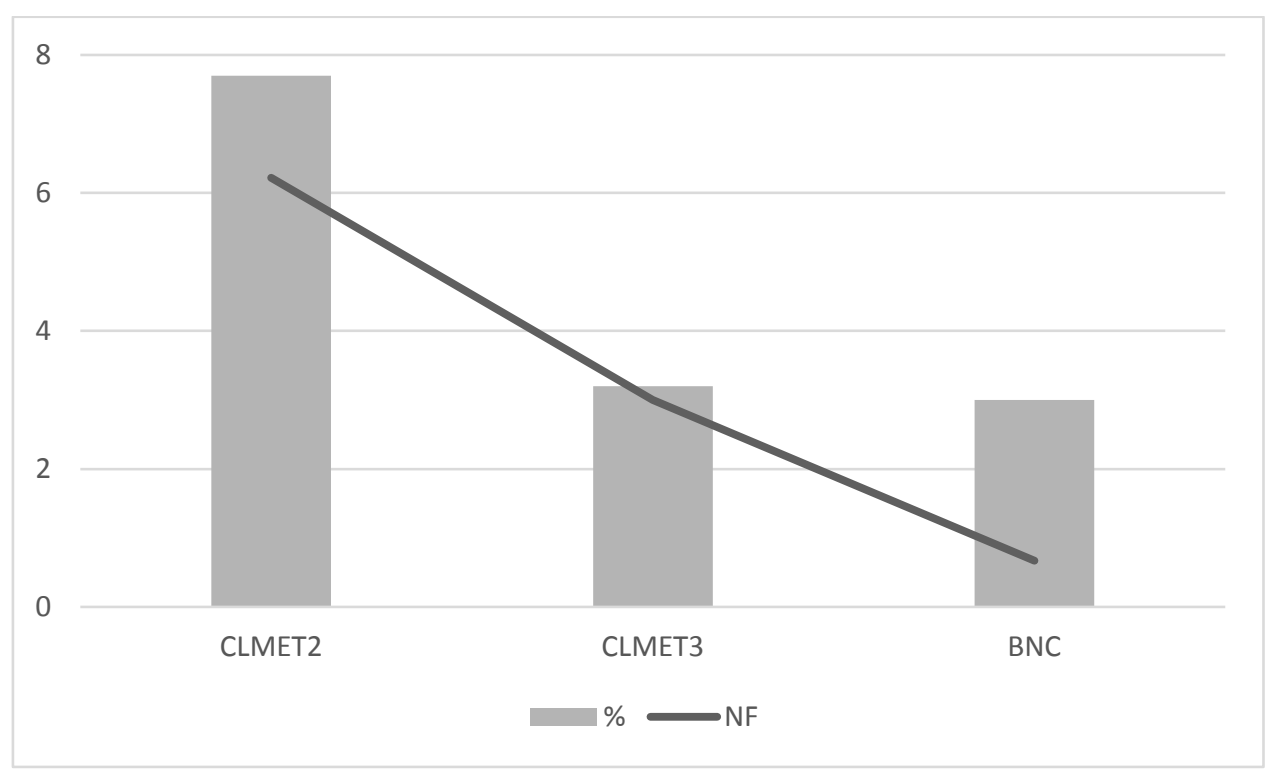

Figure 3. Normalised frequency and proportion of the -ing clause complement in the subcorpora.

The -ing clause is often regarded as a rival of the to-infinitive as a result of some of the developments in the Great Complement Shift (see e.g. Rohdenburg 2006; Rudanko 2012; Vosberg 2009). However, propose appears to be a counterexample to the theory, as the use of the to-infinitive as a complement of propose has increased at the expense of the -ing clause (and other sentential complements). According to Vosberg (2009: 217), after the -ing form has established itself as a complement of a particular verb, it can have been "felt to be semantically inadequate", which has resulted in a decline. Although the current data do not show how the -ing 
clause gained ground as a complement of propose, the decline was clearly on-going between 1780 and $1920 .^{4}$

The other -ing clause pattern in the data is the possessive + -ing clause complement, which was only found in three tokens, all from the CLMET2:

(17) In appointing a morning's or an evening's walk, he proposed $\underline{\text { HER }}$ [sic] going with the rest; no one had ever required her company before. (CLMET2: 1796 Inchbald, Nature and Art)

The pattern was mentioned in both Poutsma (MS, s.v. propose) and Biber et al. (1999: 742), but on the basis of the current data it seems to have disappeared from use or become extremely rare.

\subsubsection{That-clause patterns}

The second most common sentential complement of propose in all three subcorpora is the that-clause. It can follow propose on its own or the recipient of the proposal can be inserted between the two items in the form of to + NP:

(18) I propose that it should be treated as a case of criminal kidnap until we have evidence to the contrary. (BNC: CEC 3169)

\footnotetext{
${ }^{4}$ See Fanego (2007: 182-186) for a discussion on propose and the development of the -ing clause complement. In her $18^{\text {th }}$-century data -ing clause complements are recorded with propose in sense 2 "in ten cases, to-infinitives only in five."
} 
(19) In consequence of this reasoning, Cecilia formed a design of proposing to her companions that they should give a prize... (CLMET2: 1796-1801 Edgeworth, The Parent's Assistant)

The latter variant of the complement is surprisingly infrequent, considering it was mentioned in all three grammars. The to $+\mathrm{NP}+$ that-clause pattern has seven tokens in the CLMET2 and two in both the CLMET3 and the BNC: even in the CLMET2 it only accounts for $2.3 \%$ of all complements of propose.

The straightforward that-clause, on the other hand, is clearly more common with 53, 37 and 35 hits. The NFs and proportions for each subcorpus are presented in Figure 4.

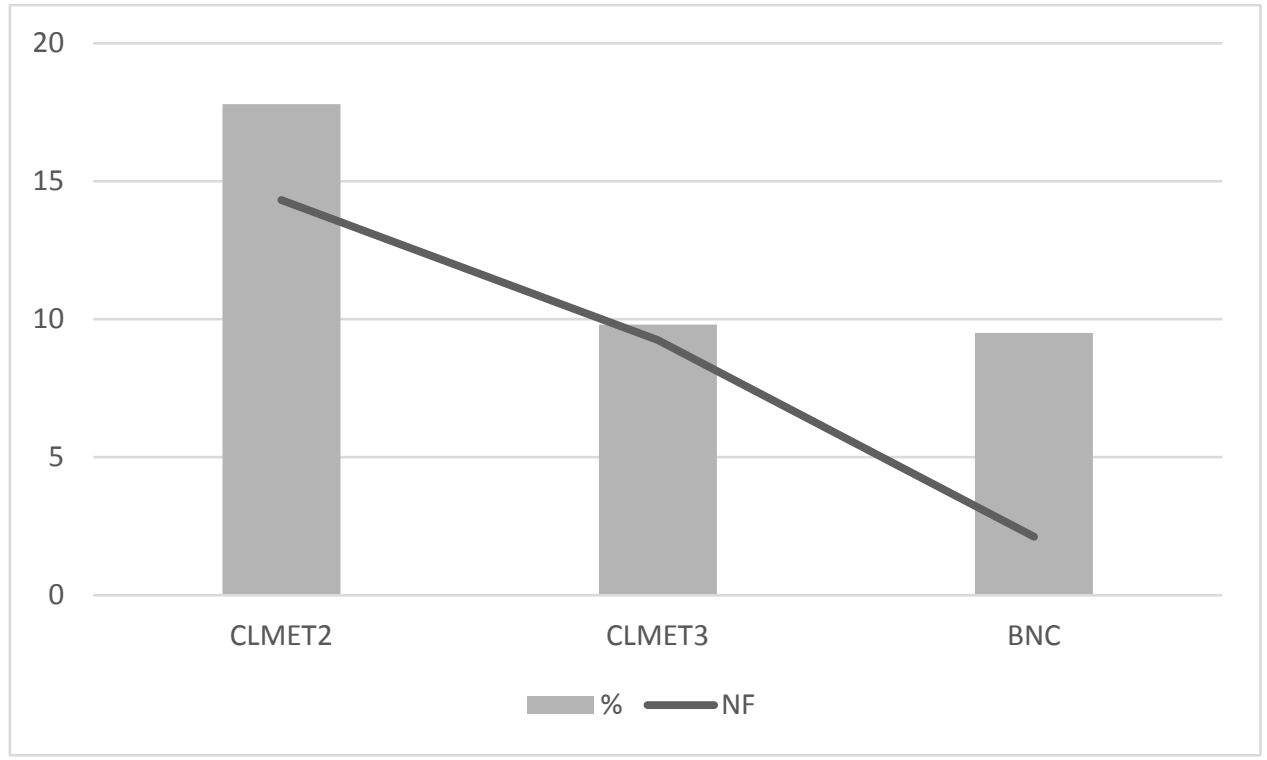


Figure 4. Normalised frequency and proportion of the that-clause complement in the subcorpora.

As the decrease in the proportions of both the that-clause and the -ing clause takes place at the same time as the increase in the proportion of the toinfinitive does, it is likely that the latter has gained ground at the expense of both of them. In general, the Great Complement Shift contrasts the toinfinitive with the -ing clause, but as Rohdenburg (2006: 143) points out, the that-clause was also affected.

\subsubsection{Other patterns}

Two other sentential complement patterns were also identified in the data, namely the quote and the wh-clause. The former has three tokens in the CLMET2 and four in the BNC, but none in the CLMET3:

(20) Mr. Towlinson proposes with a sigh, 'Amendment to us all'... (CLMET2: 1848 Dickens, Dombey and Son)

The latter was not found in the earliest data, and it had only one hit in both the CLMET3 and the BNC: 
(21) He cannot go down to Congress himself and propose what he wants: he can only write a letter and send it. (CLMET3: 1867 Bagehott, The English Constitution)

Both of these patterns are rare with propose, and were not mentioned in the literature reviewed in Section 2.

\subsection{Control}

As was established in Section 2.3, propose has an interesting and somewhat complicated control structure. Subject control is the dominant control type in all three subcorpora with both to-infinitive and -ing clause complements:

(22) ... and he proposes [he] $\mathrm{PRO}$ to hire a carriage for a whole month. (CLMET2: 1821 Galt, Ayrshire Legatees)

(23) I propose $[\mathrm{I}]_{\mathrm{PRO}}$ giving you the first call, my old friend the second, and Miss Nimmo as I return home. (CLMET2: 1780-96 Burns, The Letters of Robert Burns)

On the basis of Poutsma's remarks, some instances of object control and PP object control were also expected to be found. Both types are rare, as they are tied to the complement patterns $\mathrm{NP}+$ to-infinitive and to $+\mathrm{NP}+$ to- 
infinitive. All eight tokens of the former are examples of object control, and all 14 of the latter examples of PP object control:

(24) ....and he asked me what I meant to do with it; proposed a Charity [a Charity $_{\text {PRo }}$ to be established on behalf of decayed half-castes... (CLMET3: 1870 Meredith, The Adventures of Harry Richmond)

(25) $[\mathrm{H}]$ er suspicion had then been first excited by his displeasure at her proposing to him [he] PRo to return it... (CLMET3: 1865 Yonge, The Clever Woman of the Family)

Although the analysis presented in (25) illustrates how the NP him in the PP to him controls the subject of return, it is worth considering whether the PP is actually an element of the matrix clause or the lower clause. Rudanko (1989: 133-142) discusses similar constructions and their underlying structures. The verbs that he examines in more detail are rely on, depend on and count on. On the basis of five tests he (1989: 137) concludes that these particular verbs allow for both structures: the NP of the PP can be a part of either the higher or the lower clause, but remarks that there are verbs that only allow the interpretation whereby the NP belongs to the higher clause and an understood subject, PRO, is identified in the lower clause. According 
to the tests, some of which are illustrated in (26-28), propose seems to be of this latter type: ${ }^{5}$

(26) *What this fellow proposed to was for the Sheik to put me to death.

(27) Who did this fellow propose to to put me to death?

(28) The person who this fellow was proposing to to put me to death was the Sheik.

In fact, Rudanko (1989: 140-142) refers to Visser's (1973: 2241ff.) list of verbs occurring in this particular pattern, and propose is one of the verbs included. However, according to Rudanko (1989: 142), the use of propose in the to + NP + to-infinitive pattern is “[v]ery marginal”, which seems to be a correct assessment, considering that propose did not occur with this complement in the most recent data.

The final type of control listed by Poutsma (MS, s.v. propose) is unspecified control, in which the controlling element is not present in the sentence. In the CLMET2, there are at least ${ }^{6}$ four instances of this control type with to-infinitives and two with -ing clauses:

\footnotetext{
${ }^{5}$ Examples (26)-(28) are modified versions of the following token from the CLMET2: "My donkey-boys afterwards said they had overhead [sic] this fellow propose to the Sheik to put me to death...” (CLMET2: 1844 Kinglake, Eothen).

${ }^{6}$ I say at least because in some cases even a larger context does not reveal whether subject or unspecified control was intended.
} 
(29) I propose to cut all the timber we want for the houses out of this part of the grove... (CLMET2: 1841 Marryat, Masterman Ready)

(30) He proposed sending delegates to entreat the assistance of other Trades Unions in other towns. (CLMET2: 1848 Gaskell, Mary Barton)

If we recall the method introduced in Section 2.3 whereby non-finite clauses are converted to finite that-clauses, the sentence in (29) might begin with "I propose that we cut...” and (30) with "He proposed that we/they send...” In (29) the preference for control involving both the speaker and the hearer is made stronger by the personal pronoun we functioning as the subject of want in the subordinate clause.

Duffley (2000: 221) readily recognises the possibility of this unspecified control with the -ing clause complement. He (ibid: 237) notes that the subject of the -ing clause complement is defined by the semantics of the matrix verb, "the grammatical meaning of the -ing, and the function of the -ing with respect to the matrix". He gives an example with propose: "He proposed seeing a psychiatrist.”, and states that the action expressed by the -ing clause is "logically understood” (ibid: 238) as not being done by the person proposing it. Duffley also recognises the possibility of a sentence allowing a reading of both subject and unspecified control, especially with limited context. 
Duffley's approach to the to-infinitive, on the other hand, is slightly different. He argues that "when the to-infinitive is used as a complement of another verb, it always has the same 'subject' as the matrix" (ibid: 235), which does not seem to be in agreement with the data presented in the current study and Poutsma's (MS, s.v. propose) observation of "the subject of the action indicated by the infinitive" being "the speaker(s), the person(s) spoken to, or the speaker and the person(s) spoken to together”. Duffley (ibid: 240) gives an example, "John said to be careful”, which, as he points out, "looks like a counterexample" to the theory of -ing clauses being the only type of complement allowing unspecified control. He explains that in the example sentence, the to-infinitive is different in function from the toinfinitive in the subject control construction "John tried to be careful." This shows that Duffley recognises two types of to-infinitives: those that allow unspecified control and those that only take subject control. He concludes that other verbs behaving similarly to say are also verbs of communication. He does not use propose as an example, but it does fall into the same category. As with -ing clauses, "the interpretation depend[s] on the lexical content of the matrix" (ibid: 242).

As regards the development of unspecified control over time, its use increases notably in the CLMET3: a total of 36 cases were identified as likely cases of unspecified control with the to-infinitive and two with the ing clause (as opposed to four and two in the CLMET2). However, of these, 20 came from Booth's In Darkest England and the Way Out: 
(31) I have already described how I propose to deal, in the first case, with the mass of surplus labour which will infallibly accumulate on our hands as soon as the Shelters are more extensively established and in good working order. But I fully recognise that when all has been done that can be done in the direction of disposing of the unhired men and women of the town, there will still remain many whom you can neither employ in the Household Salvage Brigade, nor for whom employers, be they registered never so carefully, can be found. (CLMET3: 1890 Booth, In Darkest England and the Way Out)

Thus, in addition to the steep increase in to-infinitive complements, Booth's text plays a major role in the use of unspecified control in the CLMET3.

In the BNC unspecified control was identified in 12 to-infinitives and four -ing clauses:

(32) That was before Stonehenge, in 1980, became enclosed in a concentration camp cage, designed to keep people out, not in, and that fence was built before a Frenchman proposed to preserve the crumbling Sphinx by encasing him/her/it in a transparent plastic skin. (BNC: FET 2205)

(33) Well, someone got up and said I couldn't propose throwing redcoats out of Belfast because there weren’t any nowadays. (BNC: A0U 419) 
16 instances means that unspecified control occurred in $12 \%$ of all tokens of to-infinitive and -ing clause complements in the BNC. The number is $6 \%$ for the CLMET2 and 22\% for the CLMET3. If Booth’s text is left out of the calculations, the percentage is 15 for the CLMET3, which suggests that the major change happened between 1780 and 1920, as can be seen from the summary in Table 4. One reason for the increase of the unspecified control type might be the decrease of sentential complement patterns with the object of the proposal, i.e. to + NP, spelled out.

\begin{tabular}{|l|l|l|l|l|}
\hline \multirow{2}{*}{ Subcorpus } & \multicolumn{2}{|c|}{ Subject control } & \multicolumn{2}{c|}{ Unspecified control } \\
\cline { 2 - 5 } & Raw count & Proportion & Raw count & Proportion \\
\hline CLMET2 & 92 & $94 \%$ & 6 & $6 \%$ \\
\hline CLMET3 & 100 & $85 \%$ & 18 & $15 \%$ \\
\hline BNC & 123 & $88 \%$ & 16 & $12 \%$ \\
\hline
\end{tabular}

Table 4. Control in the to-infinitive and -ing clause complements of propose in the three subcorpora. The numbers exclude Booth's text.

If we return briefly to Duffley's (2000: 237) comment on the semantics of the matrix verb determining the understood subject, we can expect to find differences between the senses of propose presented in Section 2.1 in terms of control. In fact, in her research on "clauses [that] 
involve an unspecified or non-controlled interpretation of the missing subject”, Fanego (2007: 178-186) looks at the history of propose and control. She found that in sense 1 , "[t] set before oneself as something to be done; to intend, purpose, or design", ${ }^{7}$ propose used to take to-infinitive complements "and qualifie[d] as a subject-control verb" (ibid: 182). The -ing clause complement began to be used once sense 2, "[t]o put forward or suggest as a scheme, plan, or course of action; to recommend or advocate that something be done”, emerged in the 17th century. Fanego concludes that "[i]n the course of the Late Modern period and the twentieth century, the gerund steadily consolidated itself as a very frequent option for the coding of non-finite object complements without a specific controller" (ibid: 184).

Although, on the basis of the current study, Fanego's conclusion does not hold true for propose anymore, unspecified control does indeed occur almost exclusively with sense 2 in the three subcorpora:

(34) So I propose confining our attention to the elementary rules. (CLMET3: 1909 Jerome, They and I)

Although control is closely related to the senses of propose, the increase of unspecified control in the current study cannot be pinpointed to

\footnotetext{
7 These are the senses as given in the OED Online. Fanego's (2007) definitions are worded slightly differently, as she has used a different version of the $O E D$.
} 
the senses, as sense 2 has not increased in proportion to sense 1 between 1780 and the 1990s, as can be seen from Table 5. The increase of sense 2 in the CLMET3 is again explained by Booth’s text.

Table 5. To-infinitive and -ing clause complements in relation to senses 1 and 2 in the subcorpora.

\begin{tabular}{|l|l|l|l|l|}
\hline \multirow{2}{*}{ Subcorpus } & \multicolumn{2}{|c|}{ to-infinitive } & \multicolumn{2}{c|}{-ing clause } \\
\cline { 2 - 5 } & Sense 1 & Sense 2 & Sense 1 & Sense 2 \\
\hline CLMET2 & 52 & 22 & 17 & 5 \\
\hline CLMET3 & 91 & 61 & 6 & 6 \\
\hline BNC & 103 & 23 & 7 & 3 \\
\hline
\end{tabular}

\section{Conclusions}

The data suggest that major changes have taken place in the sentential complementation of propose between 1780 and 1920, after which the situation stabilised despite the verb becoming much less frequent overall. The to-infinitive has been the most common sentential complement of propose for the whole time period studied, and it strengthened its position further during this time. As the -ing clause complement has decreased in 
use, propose is an example of a predicate that goes against the general tendencies of the Great Complement Shift.

In addition to the -ing clause, all other sentential complement patterns have also decreased in use, not just in terms of NFs, but also in proportion to non-sentential complement patterns (see Figure 5). Exceptions to this are the wh-clause, which only occurred once in both the CLMET3 and the BNC, and the quote, which did not occur in the CLMET3 at all, but reappeared in the BNC.

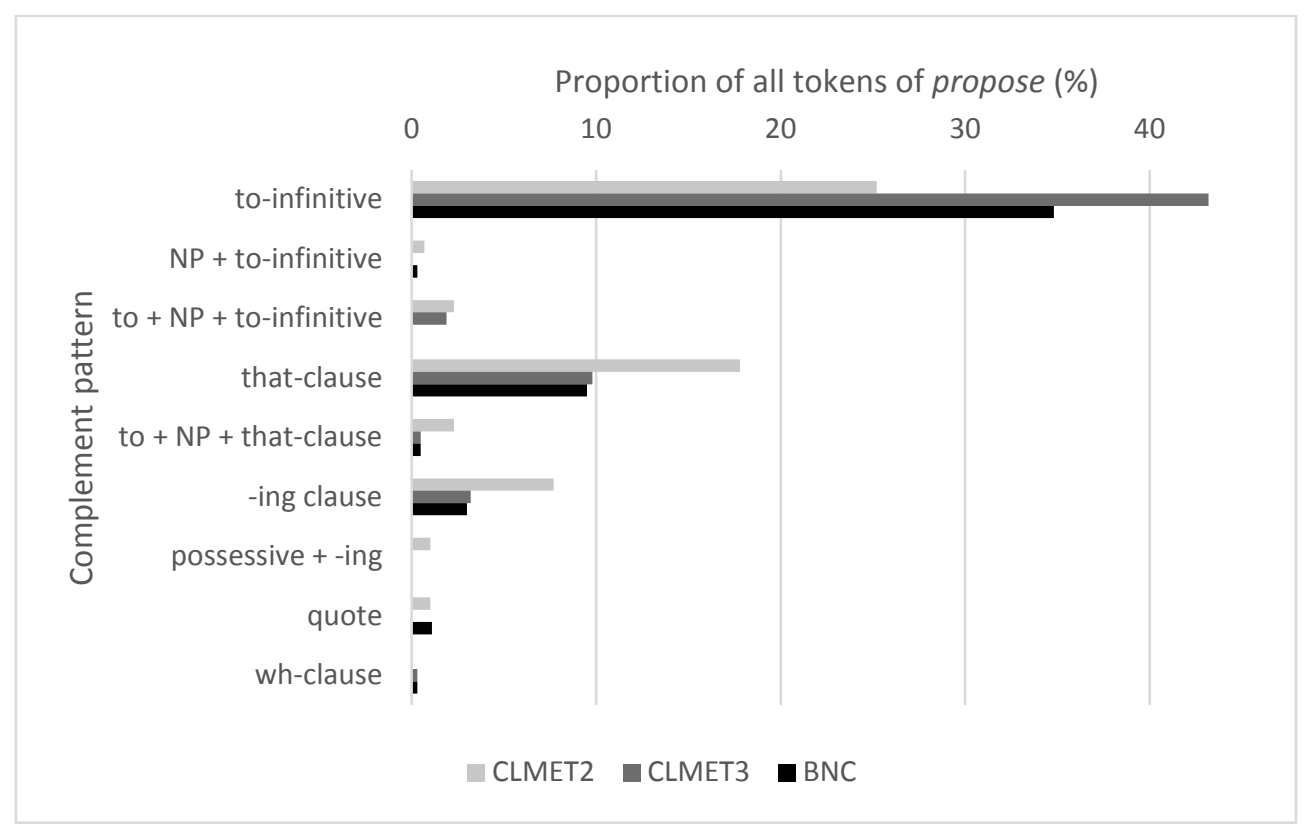

Figure 5. Changes in the proportions of the sentential complement patterns of propose in the subcorpora.

The control structure of propose is diverse, as expected after the review of the literature in Section 2.3. Examples of all four control types 
were found in the data. Subject control is clearly the most frequent of the types, whereas object and PP object control are related to the infrequent complement patterns NP + to-infinitive and to $+\mathrm{NP}+$ to-infinitive. The latter pattern did not occur in the most recent data, which resulted in the loss of PP object control. Unspecified control increased in use over time following the pattern of the complements: a steep increase from the CLMET2 to the CLMET3 and stabilisation during the twentieth century.

The observations made here shed new light on the diachronic changes in the complement patterns as seen in British English. More work can still be done on the use of propose, using larger sets of data of different types of texts as well as regional varieties to establish a timeline for the diachronic development of the complement system of propose from the perspective of World Englishes - further research of this type is invited.

\section{References}

Bach, Emmon. 1979. Control in Montague grammar. Linguistic Inquiry 19: 515-531.

Bach, Emmon. 1980. In defense of passive. Linguistics and Philosophy 3: 297341. 
Biber, Douglas, Johansson, Stig, Leech, Geoffrey, Conrad, Susan \& Finegan, Edward. 1999. Longman Grammar of Spoken and Written English. Harlow: Pearson Education Ltd.

British National Corpus. $<$ https://bncweb.lancs.ac.uk $>$

Corpus of Late Modern English Texts.

<https://perswww.kuleuven.be/ u0044428/clmet.htm>

Davies, William D. \& Dubinsky, Stanley. 2004. The Grammar of Raising and Control: A Course in Syntactic Argumentation. Oxford: Blackwell.

Duffley, Patrick J. 2000. Gerund versus infinitive as complement of transitive verbs in English: The problems of 'tense' and 'control'. Journal of English Linguistics 28(3): 221-248.

Fanego, Teresa. 2007. Drift and the development of sentential complements in British and American English from 1700 to the present day. In 'Of Varying Language and Opposing Creed': New Insights into Late Modern English [Linguistic Insights Series 28], Javier Pérez-Guerra, Dolores González-Álvarez, Jorge L. Bueno-Alonso \& Esperanza Rama-Martínez (eds), 161-235. Bern: Peter Lang.

Haegeman, Liliane. 1991. Introduction to Government and Binding Theory. Oxford: Blackwell.

Huddleston, Rodney \& Pullum, Geoffrey K. 2002. The Cambridge Grammar of the English Language. Cambridge: Cambridge University Press.

Oxford English Dictionary Online. September 2013. Oxford University Press. $<$ http://www.oed.com>. 
Poutsma, H. MS. Dictionary of Constructions of Verbs, Adjectives and Nouns. Quirk, Randolph, Greenbaum, Sidney, Leech, Geoffrey \& Svartvik, Jan. 1985. A Comprehensive Grammar of the English Language. London: Longman. Rizzi, Luigi. 1986. Null objects in Italian and the theory of pro. Linguistic Inquiry 17: 501-558.

Rohdenburg, Günter. 2006. The role of functional constraints in the evolution of the English complementation system. In Syntax, style and grammatical norms, Christiane Dalton-Puffer, Dieter Kastovsky, Nikolaus Ritt \& Herbert Schendl (eds), 143-166. Bern: Peter Lang.

Rudanko, Juhani. 1989. Complementation and Case Grammar: A Syntactic and Semantic Study of Selected Patterns of Complementation in Present-Day English. Albany: State University of New York Press.

Rudanko, Juhani. 2012. Exploring aspects of the Great Complement Shift, with evidence from the TIME Corpus and COCA. In The Oxford Handbook of the History of English, Terttu Nevalainen \& Elizabeth Closs Traugott (eds), 222-232. Oxford: Oxford University Press.

Saarimäki, Veera. 2014. The Complementation of the Verb Propose in Recent British English. M.A. Thesis. <https://tampub.uta.fi/handle/10024/96656>

Somers, Harold L. 1984. The validity of the complement-adjunct distinction in valency grammar. Linguistics 22: 507-530. 
Visser, F. Th. 1973. An Historical Syntax of the English Language. Part Three, Second Half: Syntactical Units with Two and with More Verbs. Leiden: E.J. Brill.

Vosberg, Uwe. 2003. The role of extractions and horror aequi in the evolution of -ing complements in Modern English. In Determinants of Grammatical Variation in English [Topics in English Linguistics 43], Günter Rohdenburg \& Britta Mondorf (eds), 305-327. Berlin: Mouton de Gruyter.

Vosberg, Uwe. 2009. Non-finite complements. In One Language, Two Grammars? Differences between British and American English, Günter Rohdenburg \& Julia Schlüter (eds), 212-227. Cambridge: Cambridge University Press. 